\title{
The CBMS Survey: A New Report
}

\author{
Thomas H. Barr
}

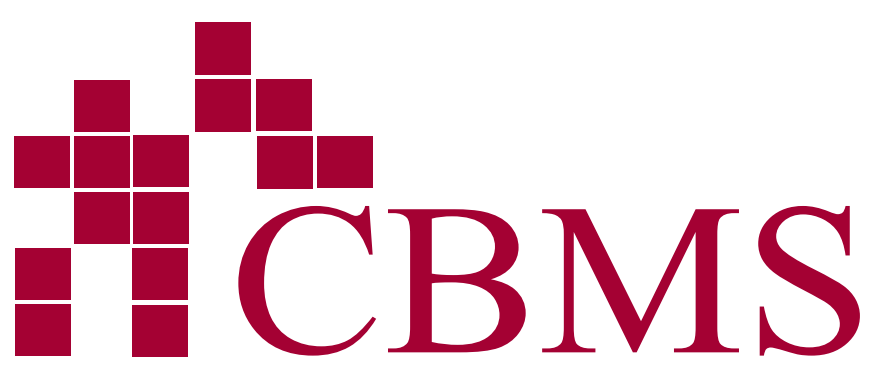

The latest report on the Conference Board of the Mathematical Sciences (CBMS) Survey was released in May, and it is brimming with both global and fine-grain information about undergraduate programs in the mathematical sciences throughout the US. This study has been conducted under the aegis of CBMS every five years since 1970 with support from the National Science Foundation. Written by Richelle Blair, Ellen E. Kirkman, and James W. Maxwell, the newest report Statistical Abstract of Undergraduate Programs in the Mathematical Sciences in the US is, like its predecessors, published by the AMS. Among the many topical areas it covers are:

- Course enrollments by mathematical subject and instructional methodology

- Characteristics of bachelors programs and degree recipients

- Characteristics of course sections and instructional staff

- Faculty demographics

In addition to tracking these factors longitudinally, the new CBMS Survey examines a number of special situations, including curricula, distance learning, and dual enrollment.

\section{A Sampling of the Findings}

CBMS is one of the few national surveys that covers mathematical sciences in two-year colleges (2YCs). Data were gathered in the 2015-2016 academic year, through a survey instrument sent to a random sample of 222 2YCs selected from the 1,031 institutions in the US with two-year math programs. Approximately $54 \%$ of the sampled departments responded. Here is a small selection of findings:

- Between 2010 and 2015, 2YC enrollment in mathematics fell by $4 \%$ to 2.0 million.

- Between 2010 and 2015, enrollments in 2YC statistics courses increased by $104 \%$ to 445,000 ; calculus enrollments nudged up by $1 \%$ to 152,000 .

- $58 \%$ of responding 2 YCs implemented pathways course sequences, which include foundations, quantitative reasoning/literacy, and statistics as alternatives to many traditional pre-college courses.

The CBMS Survey also covers mathematical sciences departments in four-year colleges and universities in the US (4YCUs). This sampling frame includes 1,470 bachelors-, masters-, and PhD-granting programs that offer degrees in mathematics, applied mathematics, statistics, mathematics education, actuarial science, computer science, and joint majors with other academic areas. These programs were stratified by degree offerings, and in academic year 2015-16, a total of 365 departments were sampled. Of these, a total of 269 responded.

Here are a few factoids regarding 4YCUs. In the study period:

- The total number of students earning bachelors degrees from all mathematical sciences departments increased by $18 \%$.

- The total number of full-time and part-time mathematical sciences faculty increased by about $7 \%$, much of that growth fueled by a $27 \%$ increase in the number of part-timers.

-Women comprised 31\% of all full-time mathematical sciences faculty, $22 \%$ of all tenured faculty, and $36 \%$ of

Thomas H. Barr is AMS Special Projects Officer.

For permission to reprint this article, please contact: reprint -permission@ams.org.

DOI: http://dx.doi.org/10.1090/noti1717 


\section{AMS COMMUNICATION}

Mathematical Sciences Enrollments in 2YCs and 4YCUs, and Math Majors in 4-yr Programs

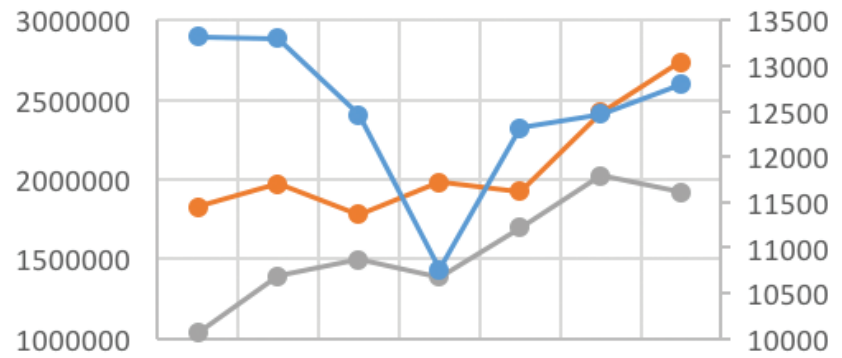

1985199019952000200520102015

$\longrightarrow$ 4YCU Math Sci Enrollments

-2 YC Math Sci Enrollments

-Math/App Math Majors

all tenure-eligible faculty-all figures up a percentage point or two from 2010.

\section{A Glimpse of the Big Picture}

The combination chart above illustrates one of the many perspectives that can be gleaned from the current report and the ones before it. This graphic focuses coarsely on two of the central elements of undergraduate education: students enrolled in mathematical sciences courses, and students graduating with degrees in mathematics. Over the span of thirty years, math enrollments in 2YCs have generally increased and more or less doubled. During the same period, mathematical sciences enrollments in 4YCUs increased by a factor of about 1.5. Along with these curves, the chart shows the numbers of "traditional" mathematics/applied mathematics majors graduating from 4YCUs. Except for a dip in 2000, these counts have hovered between 12,000 and 13,500 from 1985 to 2015. To set all of this in the wider higher-education context, in the same 30-year period, overall 4YCU enrollments grew by a factor of roughly 1.7 to about 20 million in 2015.

\section{About the Survey and Looking to the Future}

The full report is available in pdf form at www. ams.org /profession/data/cbms-survey/cbms2015, and print copies can be requested through this page. Earlier CBMS reports are also housed here. Discussions are already under way for a similar study in 2020, and suggestions or questions to the steering group can be made through this web page.

\section{Reference}

Richelle Blair, Ellen E. KirKman, and James W. MAXWELL, Statistical Abstract of Undergraduate Programs in the Mathematical Sciences in the US, American Mathematical Society, Providence, RI, 2018.

\section{Find the} data of interest to you! www.ams.org/annual-survey

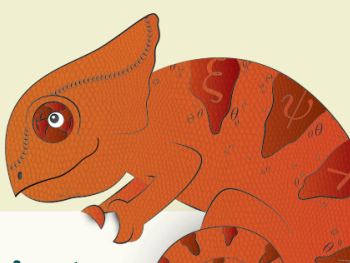

New Doctoral Recipients

Find out about new $\mathrm{PhD}$ graduates, their employment plans, demographics, and starting salaries.

\section{Doctoral Degrees and Thesis Titles}

See a listing of $\mathrm{PhD}$ graduates, their thesis titles, and where they earned their degrees.

\section{Faculty Salaries}

See the recent academic salaries for full-time tenured and tenure-track Mathematical Sciences faculty.

\section{Recruitment \& Hiring}

Get a comprehensive picture of the academic job market in the Mathematical Sciences.

\section{Departmental Profile}

Learn about the number of faculty in various categories, undergraduate and graduate course enrollments, the number of graduate students, and the number of masters and bachelors degrees awarded in the Mathematical Sciences.

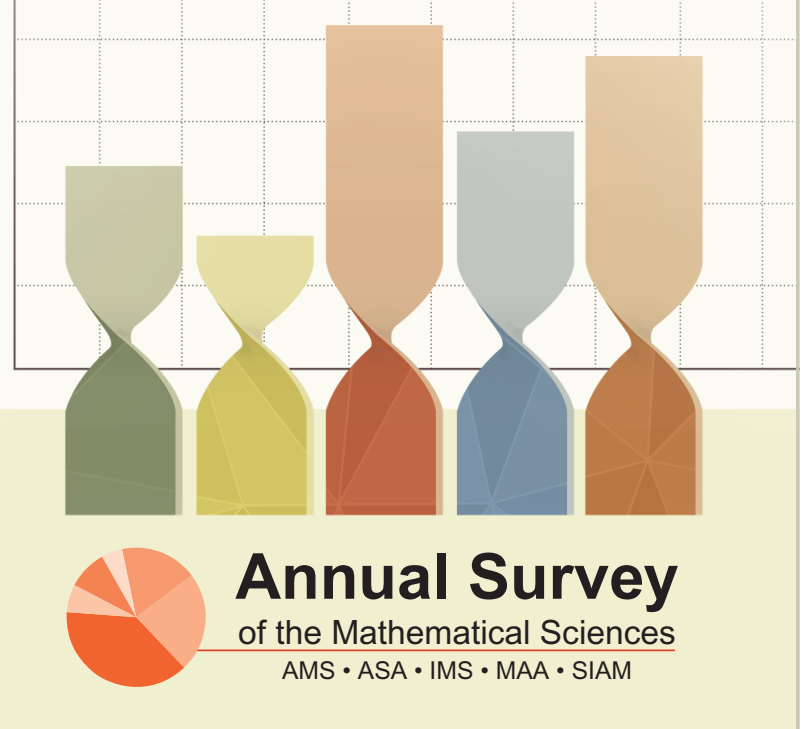

